\title{
Aesthetic Perspectives in Group Decision and Negotiation Practice
}

\author{
Edoardo Fregonese ${ }^{1} \mathbb{D} \cdot$ Isabella M. Lami ${ }^{2}$ - Elena Todella ${ }^{1}$
}

Published online: 23 July 2020

(c) The Author(s) 2020

\begin{abstract}
This paper explores the role of the aesthetics in Group Decision and Negotiation (GDN) practice, specifically how it affects the methods and the cognitive processes in the architectural field. We intend aesthetics as "scientia cognitionis sensitiva", a particular process and way of knowing and experiencing the problem through senses, imagination and empathy. We argue that (a) aesthetics and aesthetic features can (and do) convey knowledge about the problem; (b) we can distinguish between two kinds of aesthetics, one of the process and one of the product and (c) the aesthetics can contribute to create a "plural subject". The issue is investigated through a decision problem about the transformation of an iconic building in the centre of Turin (Italy), in two ways: (1) by merging the Strategic Choice Approach (SCA) with architectural design and (2) by approaching the same issue with Storytelling, as a method for problem-based instruction. Considering the aesthetics as a specific form of language, the paper offers innovative considerations about the role of representation and visualisation tools and models-drawing, scheme, diagrams, but also video and text - as support for group decisions and negotiations, in the construction of knowledge within decisional processes.
\end{abstract}

Keywords Aesthetics $\cdot$ Strategic Choice Approach (SCA) - Storytelling $\cdot$ Knowledge construction

Elena Todella

elena.todella@polito.it

1 Architecture and Design Department, Politecnico di Torino, Viale Mattioli 39, 10125 Turin, Italy

2 Interuniversity Department of Regional and Urban Studies and Planning, Politecnico di Torino, Viale Mattioli 39, 10125 Turin, Italy 


\section{Introduction}

Decision processes with at least two participants and both a common interest and conflicting individual goals can be framed in the field of Group Decision and Negotiation (GDN). Such processes are complex and include discussion, proposals and choice; indeed, communication and knowledge creation (Tavella and Franco 2015; Eden et al. 2017) are key to GDN processes. Moreover, support for these dynamics is central in the field.

Knowledge creation is particularly relevant in Problem Structuring Methods (PSMs) (see, for example, Franco 2013; Franco and Montibeller 2010; Tsoukas 2005, 2009). Indeed, group decision support methodologies have action implications (e.g. agreement on solutions, involvement in policies), which are one of the main intended outcomes of these workshops and interventions (see, among others, Eden 1992; Keys 2007a, b; White et al. 2016). PSMs belong to the family of facilitated modelling approaches, a term that some scholars in the field use to define approaches which combine group dialogue, facilitation and participatory modelling (e.g. Mingers and Rosenhead 2004; Franco and Montibeller 2010; Franco and Rouwette 2011; Herrera et al. 2016; Rouwette 2011; Tavella and Franco 2015). The practice of facilitated workshop to approach group dynamics' difficulties and limits is well-established and used (Franco and Nielsen 2018), to help group engaging in productive discussions and enabling a change in perspectives (Phillips and Phillips 1993).

There is extensive literature on applications of PSMs in group decision support (Cushman and Rosenhead 2004; Ackermann and Eden 2005; Franco 2008; White 2009; Franco et al. 2016; Lami and Tavella 2019). However, there is a limited debate about how aesthetics can be associated to a specific way of creating group knowledge (Linstead and Hopfl 2000; White 2006). Moreover, we still know little about how the aesthetics affects the methods and the cognitive processes in tackling problem situations with PSMs.

A quasi-experiment with MSc students in Architecture at the Politecnico di Torino about the transformation of an iconic Italian building produced insights that begins to address this limitation. We engaged in participant observation of the two approaches applied: (1) by merging the Strategic Choice Approach (SCA) with architectural design and (2) by approaching the same issue with Storytelling (ST), as a method for problem-based instruction.

Starting from the position claimed by White (2006, p. 782), for which "aesthetics is a form of language that can produce its own form of knowledge", these observations helped us to make a step further.

We have distinguished two kinds of aesthetics: one of the process, which can (and do) convey knowledge about the problem; and one of the product, which can contribute to create a "plural subject". We discuss the aesthetics of the process highlighted by SCA combined with architectural drawings, as a way of structuring cyclic processes of conflicts and negotiations; and the aesthetics of the product made visible by ST, embedded in the narrative itself. It is also necessary to mention the originality of the artefacts analysed in the ST: not only the "story" 
that is created but also the video made by the students, not intended as a recording of the workshop, but as a real output; whose nature lends itself particularly to the verification of the contribution of aesthetics.

As for the aesthetics of the process, we highlight the role of representation and visualisation tools and models-drawings, schemes, diagrams, but also videos and texts - in the construction of knowledge within group decision processes related to an urban transformation. These aesthetic features of representation tools and models can be analysed in terms of their ability of rearranging the existing situation or introducing new elements in the process (White 2006), in order to increase the awareness and participation to the practice itself. Aesthetics as a process of knowing lies in the ability of making contents visible and concrete, through models and representation tools, as a tangible "source of group discussion and negotiation" (Franco 2013, p. 730). We consider aesthetics as a way through which individuals within the group can communicate some knowledge about something that is not already existent and about what something could be (Consoli 2015), as in every urban and architectural design process. This communication then allows to establish that kind of knowledge as a group knowledge through which a group action is possible (Bratman 1999, 2014). Therefore, PSMs have their own aesthetics and kind of knowledge. On the one hand, they are meant to reach shared decisions in the group interaction, and then to perform a joint action in order to change the world as we know it; on the other, they are often analysed on the basis of the role of the products on which the interaction takes place in the process, trying to identify which characteristics make them effective in achieving decisions.

As for the aesthetic of the product, we observe that, from a philosophical perspective, one of the aims of both GDN practice and PSMs (the achievement of a shared decision among individuals in a group) can be translated in terms of social ontology (a branch of philosophy, Searle 1995). To reach a shared decision means that all the participants involved jointly accept to act as one individual. The concept of "plural subject" (Gilbert 2014) can be fruitful for this analysis. A plural subject is a social group irreducible to the mere sum of its members, it is a subject, able to act and to decide, it is not just an "aggregate". Furthermore, the feature of the irreducibility of the plural to the singulars is achieved through what Gilbert define as "joint commitment". It is when two or more individuals jointly commit themselves in performing such and such actions to achieve this or that. We claim with Franco (2013) that artefacts are helpful in decision-making, and through artefacts-which in the case of this paper are scheme, diagrams, PowerPoint presentations, videos, etc.-it is possible to create a "plural subject" between participants involved (Lami et al. 2014).

The paper, after this introduction, is articulated in other five sections. The second section briefly introduces the notions of aesthetics, SCA and ST. The third one illustrates the method, with the research setting, design and the data collection and data analysis. The fourth section describes the findings, with detailed depictions related to the two approaches. The fifth one discusses the findings, distinguishing the aesthetics of the processes and of the product. The last section summarised the conclusions, pointing out possible future researches. 


\section{Theoretical Background}

\subsection{A Definition of Aesthetics}

Aesthetics is a branch of philosophy, it is a word that derives from the ancient Greek

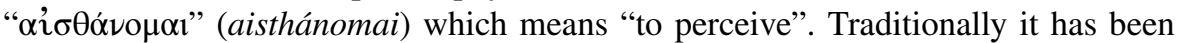
attached exclusively to the appreciation of artworks (i.e. a painting, a poem, a sculpture, a musical composition); one of its major tasks has been to explain concepts such as the one of Beauty, or to give a taxonomy of the Beaux Arts.

In the mid-eighteenth century, A. G. Baumgarten, a German philosopher, pointed out that aesthetics can be conceived as the "scientia cognitionis sensitiva" (Baumgarten 1750, p. 1). In this view, the science of sensible cognition has the disciplinary aim to explain the truth (or the opposite) of a knowledge acquired through the "lower" faculties of the mind (not mathematics or pure metaphysical thinking, but through senses, and imagination). This meaning of aesthetics emerged strongly in the 60s (starting from the work of Andy Warhol), when philosophers argued that aesthetics could not be more fruitful in the distinction between a mere object and an artwork: since then art is no more committed with the idea and concept of beauty. Art became something metaphysical: sense, perceptions and the nude eye cannot distinguish anymore between a box of soap and a work of art (Danto 1981). At the same time, a quasi-autonomous discipline related to a branch of cognitive psychology was emerging cognitive sciences, dealing with issues about mind, brain, neurons, and any entity that has to do with our way of conceptualizing the world. The role of perception was detected as central in mental processes and aesthetics met cognitive sciences (Consoli 2015).

In this respect, a branch of aesthetics (Friend 2006; Livingstone 2009; Mar and Oatley 2008; Walton 2013) looks at the way through which we augment our knowledge using fictions. As a general definition, we can state that the imagination can give us knowledge during a learning process: the fiction is a simulation (reality-oriented), without reference to anything actually existent (Consoli 2015). Moving up through the terms of the proposed definition, we encounter "simulation (reality-oriented)". As stated by psychologists (Mar and Oatley 2008)_focusing their study on fiction literature-fictional simulation through abstraction, compression, and simplification give us models of the social world. In this sense, the imagination-intended as an aesthetic faculty-is oriented to reality, despite the fact that it is a simulation. Indeed, we know something about social interactions and experiences, precisely as experienced by the fictional characters of the story.

Imagination is a form of modal knowledge: it consists in figuring something and exploring it by different points of view (Phillips and Phillips 1993; Friend and Hickling 2005). If we consider, for instance, a building that has yet to be built, we explore many possibilities, we imagine them, and through this during this process we acquire some knowledge about the possible future of the building. This happens despite the fact that it does not exist yet. In this sense, our imagination-and every related artefact-has not a referential power: it refers to something that is not actual, still it produces knowledge. 
Summing up, aesthetics is a way through which we can communicate some knowledge about something that is not already existent. The kind of knowledge related to aesthetics and imagination is an exploration of manifold possibilitiesand through scheme, diagram, text, and video (artefacts in general) we can acquire knowledge of what is possible.

\subsection{Strategic Choice Approach}

In the minds of the pioneers of Strategic Choice Approach (SCA), the method is intended as "a useful framework for reflection and learning as well as action" (Friend and Hickling 2005, p. 343), in responding to complex decision problems. They conceive a process of strategic choice essentially as a learning process, through which problem perception is facilitated and new knowledge and perspectives on the problem can emerge. Then, SCA in itself allows an expression of the problem in more accessible forms, that produces a better understanding and a shared knowledge at a collective level (Friend and Hickling 2005), with the production of stronger and more shared decisions among participants in a group.

The paper investigates SCA in its possible interface with architectural design, as a way of structuring and cooperating with the design process (Todella et al. 2018; Tavella and Lami 2019; Lami and Tavella 2019). SCA and architectural design process can be both intended as cyclic and "in progress" process of conflicts and negotiations (Armando et al. 2015; Todella et al. 2018) and "running labs" about realworld problems (Latour and Woolgar 1979; Latour 1988). Moreover, SCA modes and phases are similar to the way architects think and draft alternatives (through sketches and drawings), even if in architectural design there is not a formal definition of different steps to define a transformation project.

In this sense, by using SCA in a merging with architectural design we recognise a specific aesthetics_-as sensitive knowledge (Baumgarten 1750)_linked to the models and the language used, that can be "considered as legitimation of both the individual and the group thinking and knowledge" (Todella et al. 2018, p. 821). We then consider architectural design tools as a contribution to the creation of "invisible products" in SCA (Friend and Hickling 2005). In this, a shared problem definition, values and perceptions enable to enlarge the participants' knowledge and consequential shared decisions about the problem situation. Consequently, we argue that architectural design tools-drawings, schemes, diagrams, but also videos and texts - contribute to the construction of a better shared reality (Todella et al. 2018), thanks to the models' capability of transferring and translate knowledge (Pidd 2003; Franco 2013) and of enabling a wider understanding of the real problem.

\subsection{Storytelling}

Many philosophers in the history of philosophy dealt with the issue of "narrative", starting from Aristotle in his Poetics. One of the most important conceptualizations about narrative is offered in 20th century by Ricoeur (1984), who links the issue about narration with philosophy of historiography. Another fundamental one was 
given by Goldie (2012), who wrote: "a narrative or story is something that can be told or narrated, or just thought through in narrative thinking. It is more than just a bare annal or chronicle or list of a sequence of events, but a representation of those events which is shaped, organized, and coloured, presenting those events, and the people involved in them, from a certain perspective or perspectives, and thereby giving narrative structure-coherence, meaningfulness, and evaluative and emotional import-to what is related" (Goldie 2012, p. 2). A narrative is not just a collection of events, actions and brute facts; it is something which has a kind of internal unity, a structured representation of something that does not necessary exist. However, the story could still have value despite referring to anything actual. It is no accident that narrative has been regarded as valuable of representing a reality (be it fantastic or not). Haydn White, a famous philosopher and historian, tells us that there is natural impulse within human nature to narrate, to the point that "narrative is a meta-code, a human universal on the basis of which transcultural messages about the nature of a shared reality can be transmitted" (White 1980, p. 6).

Storytelling (ST) is not fully considered a PSMs, even if some researchers tried to relate storytelling to group decision support interventions (Klein et al. 2007; Andrews et al. 2009) and very recently also in related field, as for spatial planning (Bulkens et al. 2015).

We applied ST following the hypothesis made by Tollefsen and Gallagher (2017) within the field of social ontology. They argue that the construction of a shared narrative about an action (be this action the renewal of a building or the choice of going out for dinner) can contribute to the stability of the shared intentions (Bratman 1999, 2014) of the individuals that should perform this action. The stability of the intentions leads to a "stronger" plural subject (Gilbert 2014) able to perform linearly a joint action. This is a theoretically argued thesis that we followed in the decision of applying ST in a group of MSc students, during a workshop concerning the discussion of the adaptive reuse of an historical building. The issue about the aesthetics is strictly correlated to the empowerment of a singular shared intention between participants: the formation of this can be facilitated through stories and their aesthetic way of conveying knowledge (about the issue at stake).

\section{Methods}

\subsection{Research Setting and Design}

Our study relies on data collected during a quasi-experiment with MSc students in Architecture at the Politecnico di Torino. The students were involved on a real-world case study, concerning the several options for the adaptive reuse of former Turin's Stock Exchange building (Italy). The building, inaugurated in 1956, fully belongs to the history of Italian and European architecture briefly labelled under the name of "Neo-liberty". In 1992, a single national Stock Exchange was established in Milan, then the Turin's Stock Exchange ceases its activities and remains unused. In the last years, the possible reuse of the peculiar building has been object of a real discussion among the owner, the City and the Region, ended now with the definition of 
a precise intended use but, at the time the paper is drafted, without any real start to work yet.

Being aware of the limitations of experimental research, such as the trade-off between realism and controllable and comparable situations (Franco and Rouwette 2011), and the limited students' stake in the workshop outcomes, we took several measures to raise the level of student engagement. Those steps also aimed at increasing the validity of the results and fostering as much realism as possible (Midgley et al. 2013). Firstly, a case of urban renewal that is largely debated in Turin was chosen. Secondly, the second author of this paper (the course responsible) used different learning and teaching activities to support the students in acquiring specific knowledge (about PSMs, the Stock Exchange building and urban renewals) useful for engaging in a decision-making process. Thirdly, the students were tasked to not only act and reflect as project designers, but also as developers.

The four phases of the quasi-experiment are represented below (Fig. 1). During the first stage of the study, the second author introduced the theoretical aspects of PSMs in general, SCA and ST in particular, and the case of Stock Exchange to the students; in this phase, they did not know in which group they would be during the workshops. For the second stage (the workshops) the students have been split into (initially) four comparable groups, with their age and their academic backgrounds being fairly homogeneous. Two groups discussed the decisional problems in a workshop supported by SCA, and the other two worked in a workshop supported by ST.

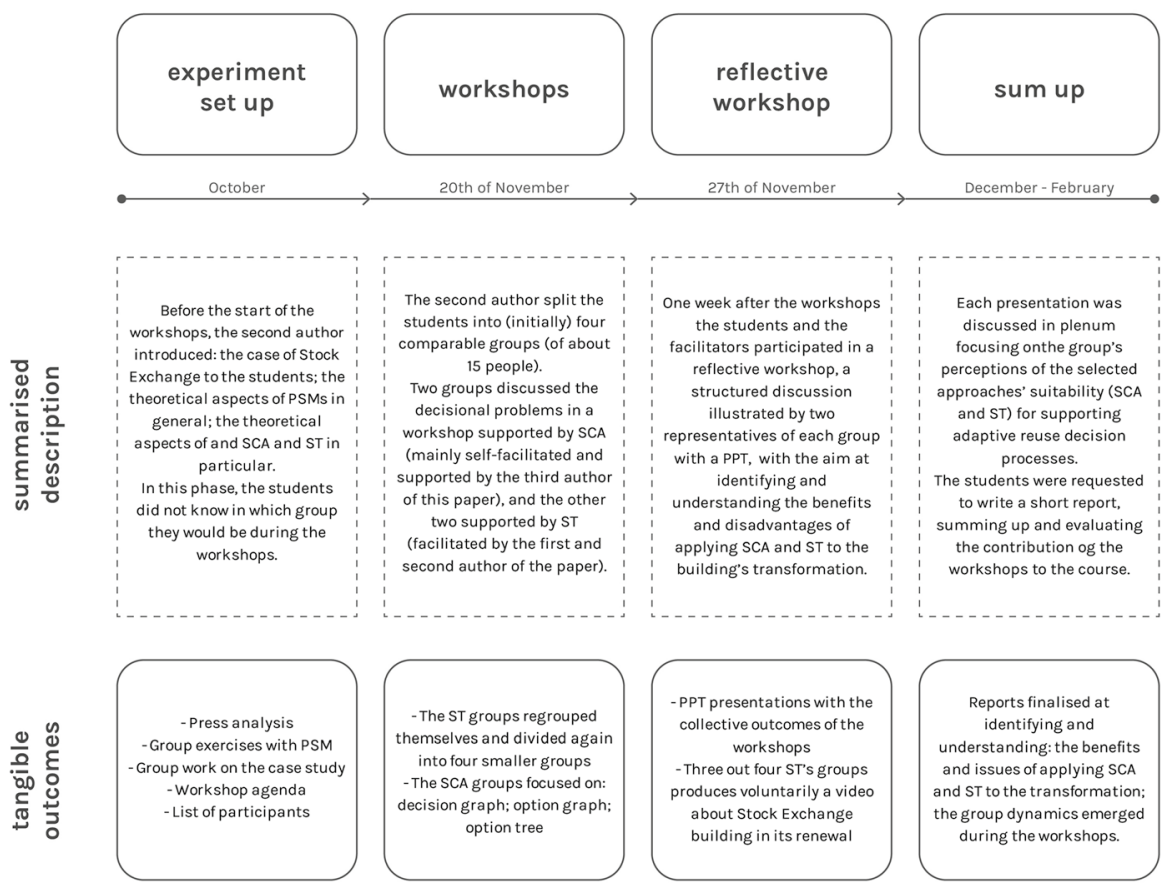

Fig. 1 Research strategies of the quasi-experiment (own elaboration based on Herrera et al. 2016, p. 1287) 
The latter, during the workshop and according to the ST methodology, regrouped themselves and then spontaneously divided again into new smaller groups, four in total. In this way, at the end of the workshops, we had outputs from six different groups, two for SCA and four for ST.

Each workshop was conducted at the same time in different classrooms. In our study, following Checkland (2001), Mingers and Brocklesby (1997) and Checkland and Scholes (1990), we adapted SCA and ST to our context, and the time availability given by the course schedule and timeframe. We focused on two different group decision support practices, in particular on an established PSMs practice as SCA and another approach that does not entirely fit into these categories, such as ST, mainly for three reasons:

1. since the fact that urban planning (and designing) is considered a wicked problem (Rittel and Webber 1973), several PSMs were potentially apt to perform a joint action, despite the fact that stakeholders involved in the process has their own different values and perspective. Having urban renewals, however, specific features (Lami 2019), we adopted SCA because it proved to be particularly suitable for the peculiar realm of architectural transformations (Friend and Hickling 2005; Todella et al. 2018; Tavella and Lami 2019; Lami and Todella 2019);

2. as the aesthetics was the focus of the research, ST is considered due to the eminently aesthetic content of its narratives, that produces knowledge through imagination (Phillips and Phillips 1993), and perform in group decision support interventions (Klein et al. 2007; Andrews et al. 2009);

3. because SCA is strictly related to the decision-making process within groups, while ST is more focused into the products of a decision-making process, we adopted them in order to analyse the aesthetic features of both the process and the product through which an action, or a decision (the renewal of a building) is devised and structured.

In particular we used just part of SCA: the participants specifically focused on (1) designing the decision graph, (2) conducting an Analysis of Interconnected Decision Areas (AIDA) by building a compatibility table or an option graph, and (3) designing the option tree for SCA (Fig. 2).
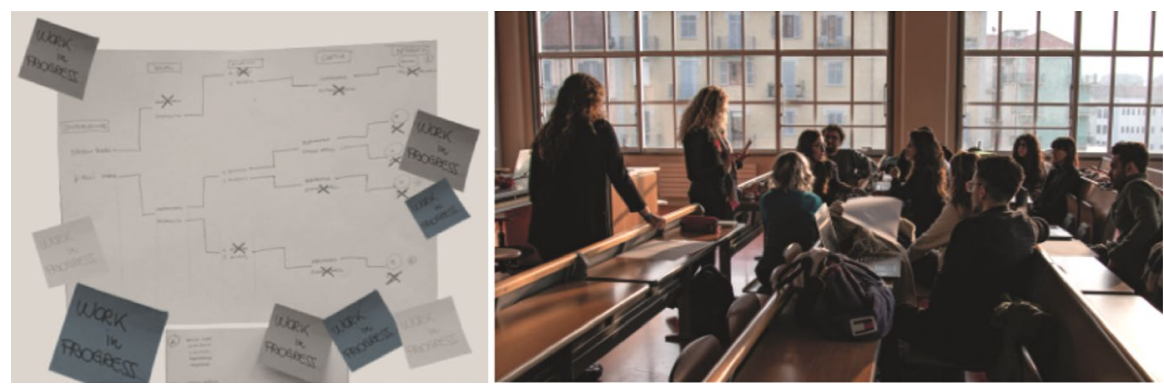

Fig. 2 One of the SCA output and a general discussion 
As for the ST, participants were asked to write guided story individually and collectively. And the ST workshop has been structured in four phases: the writing of an individual story; the reading of the story in public with a brainstorming aimed at highlighting the key words and common concepts; the creation of new spontaneous groups based on four keywords; the writing of a collective story for each group following the second story-spine.

One week after the workshops, all the students and the facilitators participated in a reflective workshop (Midgley et al. 2013), during which they discussed the process and outcomes of the workshops with the aim at identifying and understanding the benefits and disadvantages of applying SCA and ST to the transformation of the specific building in particular and adaptive reuse in general. First, two students representing each group presented the outcomes of their workshops using Power-Point slides, discussing the options for transforming the Stock Exchange building they formulated and agreed upon. Second, three out four ST's groups produces voluntarily a video about Stock Exchange building in its renewal. Finally, each presentation was discussed in plenum. Through the production of the videos, the participants found a way to merge their individual perspectives in order to create a new, more effective shared one for the group, intended as a whole - a plural subject-made by participants but not reducible to them (Gilbert 2014). In each video there is a common structure: everything (the plot, the action, the events, and so on) turns around a central point, the building.

\subsection{Data Collection}

We gathered data from three main types of sources: observations, students' field notes and reports, artefacts.

\subsubsection{Observations}

We participated to the workshops as facilitators; during which we took partial notes and pictures of people and artefacts. The workshops have been also audio-recorded and partially transcribed. During the reflective workshop (Midgley et al. 2013), we took careful notes that have been use later, in additional informal conversations with the students.

\subsubsection{Students' Field Notes and Reports}

The professor of the course (i.e. the second author of the paper) has requested each group to have an observer in charge of producing field notes during the workshop. The specific person was freely selected among the members of the group by the components themselves. The observers received some suggestions: to never interact with the group; to focus on the participants' interaction in the process through the artefacts produced; to reprocess and analyse their observations. Drawing upon overt involvement, but not performing the role of a team member stricto sensu, he/she managed to balance the roles of participant ('going native') and observer (remaining 
objective) (Spradley 1980; Stigliani and Ravasi 2018). The observers, then, annotated comments during the workshop with respect to the interaction of the participants in the process, and of the products used. These comments were then reprocessed by the observers and delivered to us a week after the workshop. Moreover, at the end of the course, we collected by each group a short report summing up and evaluating the contribution of the workshops to the course.

\subsubsection{Artefacts}

For the SCA, the decision graphs, the option trees and the final presentations have been collected from the two groups. For the ST the artefacts gathered were of four types: the individual stories (35 in total), the collective stories (4 in total), the final presentations (4) and the videos (3).

\subsection{Data Analysis}

We conducted data analysis in two steps. A first-order analysis was aimed at discovering themes and patterns in students' artefacts, field notes and report. When doing so, we initially mapped both the interaction of the students among them (and with the observers) and the interactions with the artefacts, concentrating our attention particularly on the aesthetic issues. Focusing on the role of the observer in the two different cases, it is important to emphasize that the observer is useful from an epistemological point of view to understand thoroughly and with an inside look on what is happening in the interaction of the group; moreover, the observer has a very different role from the facilitator, giving not in itself a contribution to the workshop, but just describing and analysing the interactions and the products occurred in the intervention. In the reports, the observers summarize very well both the way the participants work (in micro-groups and then collectively), and the products (photos of the work in progress and final products), so we clearly see the process unfolding. Surely the role of the observer has been of considerable importance because, without being instructed about necessarily observing specific aspects, they nevertheless made remarkable material to work on and reflect-in very relevant open debates in the field of PSMs.

The second-order analysis moved to a more abstract and theoretical level, wherein we examined the raw data and first-order findings to discover underlying dimensions that might be relevant for domains beyond this study (Spradley 1980; van Maanen 1979). Based on our first-order findings and consistent with our research question, we reinterpreted our observations in order to understand and explain how the aesthetics affects the methods and the cognitive processes. We carefully and systematically tracked episodes involving reported aesthetic issues, distinguishing an aesthetic of the process and one of the product. In order to analyse these traces, we started from the way scholars in PSMs categorize and define models as potential "boundary objects" (Star and Griesemer 1989; Eden 1992; Pidd 2003; White 2009; Franco 2013; Tavella and Lami 2018) and their performativity in facilitating or constraining group interactions. Starting from the literature, we recalled here the specific ways 
of acting and performing of boundary objects to describe the use of artefacts, during the workshop, in reaching specific effects. Boundary objects, indeed, can act by "transferring", in order to develop shared language between participants; by "translating", to develop shared meanings; moreover, by "transforming", with the aim to develop common interests among parties (Franco 2013, based on Carlile 2002, 2004).

In both stages, we complemented observational data with interview transcripts in order to enrich, reinforce and triangulate our emerging theoretical interpretations.

\section{Findings}

\subsection{The Aesthetics of the Process}

The first-order analysis focused here on the way the merging of SCA with some architectural design tools (like drawings, schemes, and models) contribute to the construction of a better shared reality and a "plural subject" in the context of group decisions and negotiations. What emerged as themes and recurring patterns in examining students' artefacts, field notes and reports can be synthesized through three specific issues:

- the artefacts use;

- the emergence of new labels and keywords during the workshop;

- group dynamics and the "trait d'union".

The first two are referred to the aesthetics' effect on the cognitive process; the third is related to the construction of the plural subject. In the following lines the three points will be briefly illustrated, as emerged on the basis of the second-order analysis and evaluation on aesthetics features' effects.

\subsubsection{The Artefacts Use and the Emergence of New Labels and Keywords}

By using SCA in a merging with architectural design tools, we recognise a specific aesthetics - as sensitive knowledge-linked to the artefacts and the representation language used. Thanks to the data collected, it is evident how the decisions are taken in the process and structured through artefacts (drawings, design schemes, models), as negotiation objects.

First, some three-dimensional models were used to describe and explore some "decision options" designed to answer the decision problems identified as "decision areas" (Fig. 3, on the left). Indeed, in the workshop's report the students give more relevance to the design products and to the project schematizations-rather than words, tables or diagrams_-as models around which organising the debate (Fig. 3, on the right).

The three-dimensional models and project schematizations act here by both showing the current opportunities and envisioning these opportunities in just few simple moves. In this sense, they transform perspectives into visual artefacts, to 


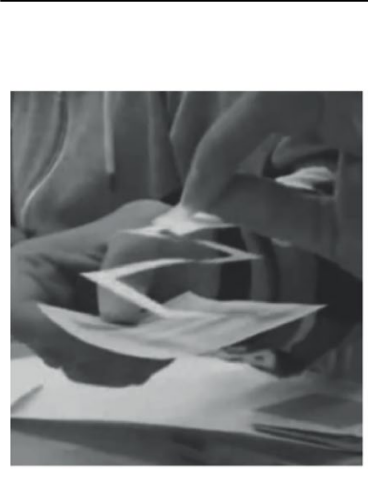

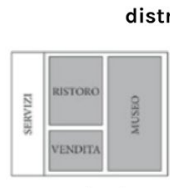

one level

new constructions

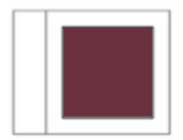

central distribution

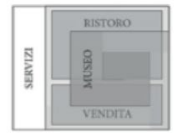

more levels

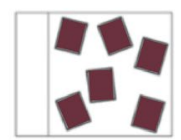

distributed

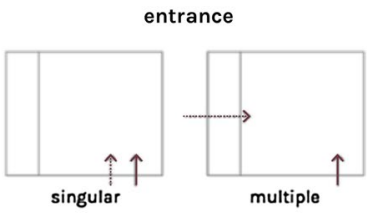

underground level

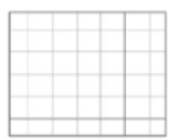

storehouse

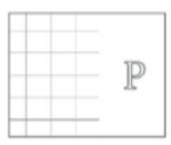

storehouse and parking

Fig. 3 Three dimensional models and project schematizations

concretely deal with them. In this sense, the multiple representations aim at traversing a pragmatic boundary, concretely resolving implications by anticipating them and transforming in practical ways the possible commitments to action. The visual artefacts acts managing - actually anticipating through spatialization, as an aesthetic feature-the conflicts related to the consequences of particular choices in the project, generated among stakeholders with different perception of the consequences of particular actions, by allowing group members to share a common perception.

Moreover, in some specific situations of the AIDA, the participants used keywords other than the typical "labels" employed in SCA, in order to better understand each other and to synthetically encompass and symbolize a series of clear and evident characteristics for the participants themselves. In particular, the keywords were related eminently to the architecture field, since some well-known architectural projects (e.g. the Mole Antonelliana, an iconic building in Turin) were used as a synthetic explanation of some actions and strategies.

In this case, a base common language is established to communicate and define relations among entities related to an issue. The keywords, used both in verbal discussion and in models' exchange, allow a new way of communicating between participants, as a more structured procedure that can help to access others' perspectives and reducing what can be identified as a syntactic boundary. The visualization aspect-as a remind to iconic and well-known buildings, and an aesthetic feature-allows to share perspectives and implies a common perceived nature of the problematic situation. Then, this use of keywords in the models exchanged and in interaction aims at transferring or communicating knowledge and has the effect of producing a shared language.

\subsubsection{Group Dynamics and the "trait d'union"}

It is then possible to compare the progressive construction of a shared knowledge in the two macro-groups (for sake of simplicity here defined macro-groups A and B), because in both cases there is a similar movement of subdivision and reunion at alternate times, depending on the current needs in the workshop.

In the macro-group A, the construction of a "plural subject" is practically immediate, it is reached very quickly thanks to a deep agreement between the participants, 
since the first joint decisions; in fact, the common decision on the intended use for the building influences the discussion in the micro-groups, that starts on a more detailed observation scale, from an architectural point of view.

In the macro-group $\mathrm{B}$, the initial discussion has a great influence on the subsequent dynamics and very often conflicts are generated. The observer traces the participants' movements and actions, and the related artefacts' use and production. There are often, therefore, some of the participants who tend to act as facilitators of the debate, trying to recompose the behaviours and decisions of the different participants; this role of moderator, moreover, shifts from one person to another depending on the moment. Albeit in a conflictual manner, the construction of a "plural subject" (Gilbert 2014) takes place progressively in the process, following each of the different discussions and conflicts, for which every resolution implies a continuation in the process (Fig. 4).
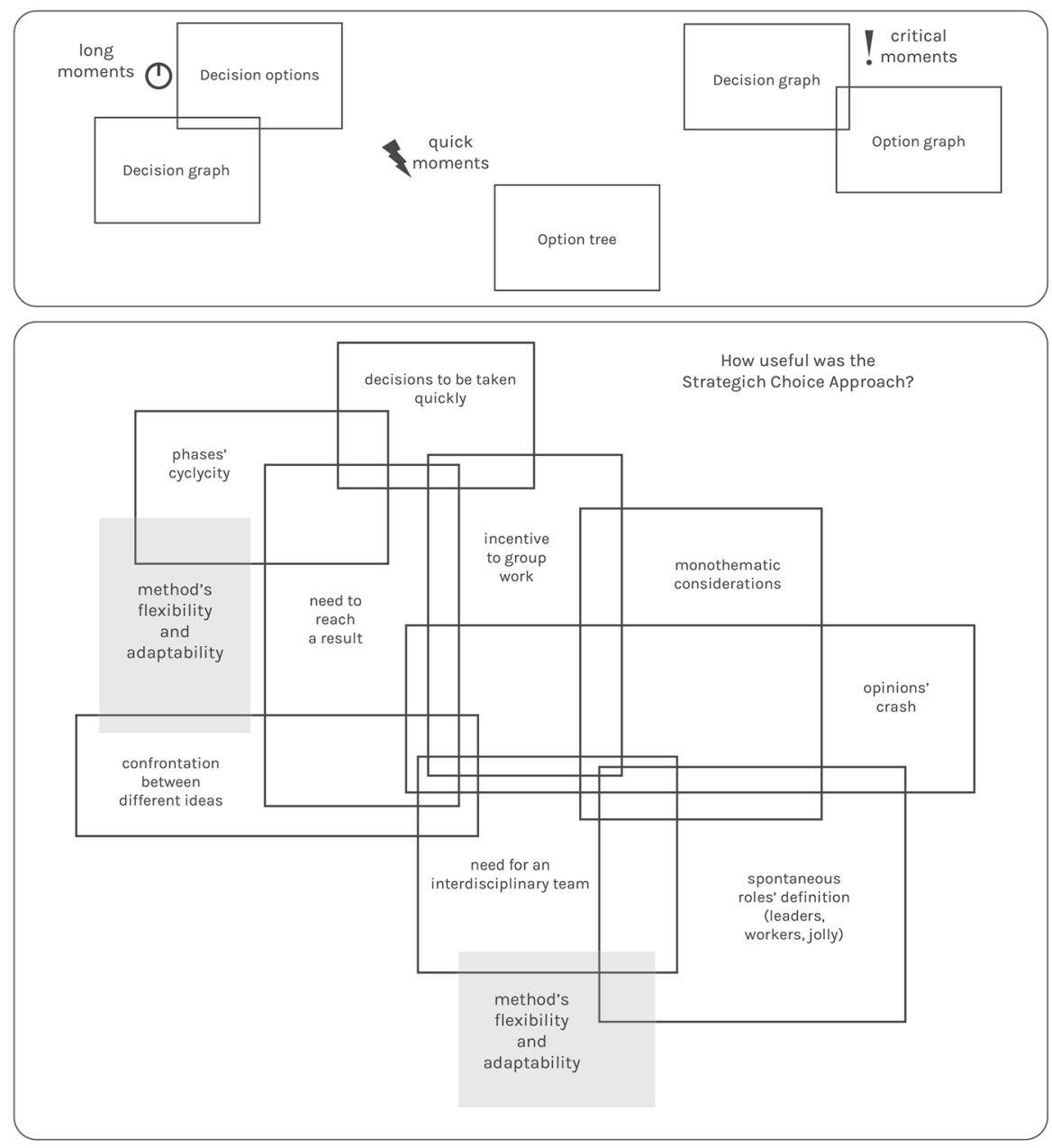

Fig. 4 Observations made by the observer about the timing and the effectiveness of the method 


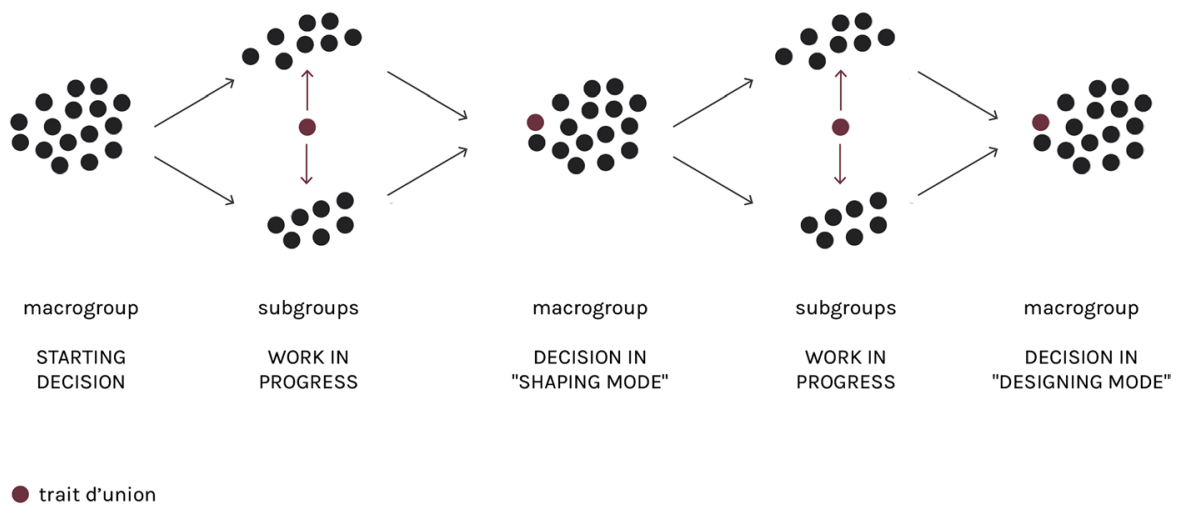

Fig. 5 Macrogroups and microgroups: SCA's "movements"

This happened also through the figure of what we called "trait d'union", who had the role of moderator and facilitator in the interface between the two subgroups, managing their conflicts and negotiations in the process. The continuity and coherence of decisions is therefore guaranteed by the presence of this spontaneous facilitator: the "trait d'union" worked as a concrete link between the two subgroups, acting as an intermediary between two separate parts which, in this way, would be able to communicate continuously and to share live the artefacts progressively discussed in the subgroups. This is reflected and recognizable in the process, as shown below (Fig. 5):

This above-mentioned dynamics of exchange among subgroups, through the sharing of concrete visual objects mediated by an emerging figure of a "trait d'union", can be traced back to the aim of translating perspectives between those involved, with the effect of creating shared meanings and interpretations among participants. In this sense, the sharing of visuals through the action of the "trait d'union", that not only help representing but translating their differences in concrete terms, can be intended as a way to traverse a semantics boundary, in order to negotiate and, eventually, overcome conflictual constraints and uncertainties.

\subsection{The Aesthetics of the Product}

The first-order analysis focused here on the way in which the product of a collective process and work, with evident aesthetic features (it is a story in the form of a video), contribute to merge the individual intentions of the participants into a collective intention shared by all of them. What emerged in this case in terms of recurring themes and issues in examining students' artefacts, field notes and reports can be organized through the following issues:

- the relation between the individual and collective stories, as emerged in the different phases of method application and related story-spines; 
- the individual and collective intentions, as assembled in the transition between the two spheres;

- the way in which the final product (the video) was able to merge the intentions of the group's participant.

The first two point can be related more to the construction of the plural subject, the last one to the aesthetics' effect on the cognitive process. In the lines below these points will be briefly illustrated, as emerged on the basis of the second-order analysis and evaluation on aesthetics features' effects.

\subsubsection{The Story-Spine in Different Phases}

In the first phase, 35 people wrote down their own reflections based on a storyspine (Table 1):

If the first question is a kind of "warm-up", the second is the central one. Here the participants had to imagine the possible futures of the Stock Exchange building by writing functions, potential users, and analogous cases. The last question calls for a return to reality. Acclimatization, main issue and imagination, and finally a return to the reality of things by asking pros and cons of every individual story, by confronting imagination with the real world - that act upon the stories as a kind of limit, in order to maintain imagination as imagination and not pure fantasy.

The first phase concluded by a half an hour brainstorming; everyone made public the individual story and the two facilitators wrote them on the blackboard, through the use of "synthetic" terms that refers to the stories-and to the possible uses of the building of the Stock Exchange (Fig. 6).

Not surprisingly, many stories were quite analogous and shared some features and elements. This brainstorming phase and the visualization of group of words-as referred to concrete aspects of the problem-allows to communicate between participants and to access others' perspective, by transferring knowledge to create a shared language. The reached shared common language helps indeed traversing a

Table 1 First story-spine for writing an individual story

\section{First story-spine}

1. Turin today has... [describe from your own point of view what elements best characterize Turin in the national and international panorama (tourism, economics, culture, etc.)]

2. Piedmont, Turin and its historical centre present a good level of services, anyway there is a lack in the... (hospitality, residential, etc.) sectors that could be satisfied by the transformation of Stock Exchange building. [describe the sectors into which imagine a feasible transformation of Stock Exchange building. Then, individuate the products, the typology of possible users and, if possible, an analogous case]

3. The main strength and weakness of Stock Exchange building with respect to the hypothetical transformation at point (2) are... [describe the element that can influence the decision of a possible public investor with respect to the hypothetical transformation at point (2)] 


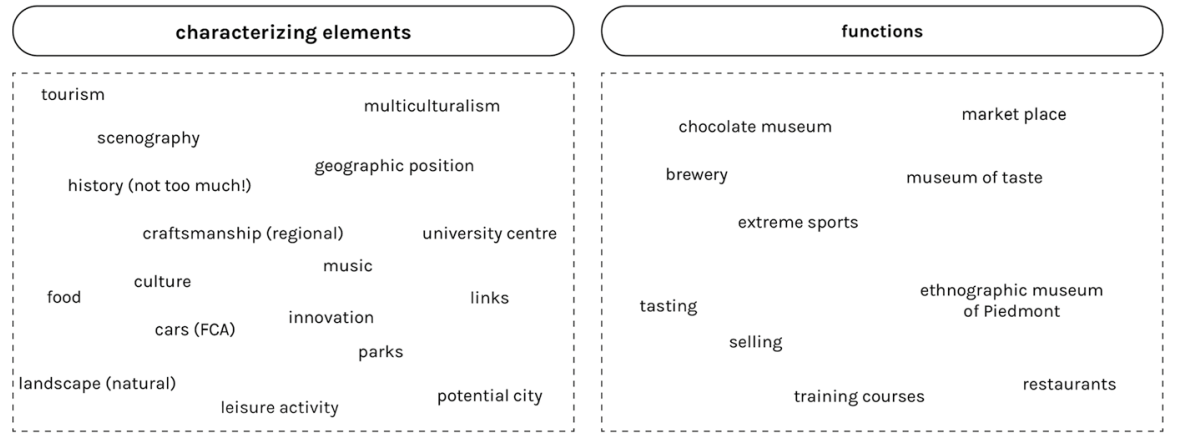

Fig. 6 Keywords extrapolated from individual stories

syntactic boundary and establishing a common perceived nature of the problematic situation.

At this point of the workshop, students grouped spontaneously by looking at the above-mentioned shared elements of their individual stories. Starting from a base of 35 participants, they created 4 groups, composed each one by $6 \div 10$ people. During the third phase each group was then asked to produce a collective story, following another story-spine (Table 2), then the students had to merge their own individual intentions to the point to create a shared one that can potentially represent every student.

\subsubsection{From the Individual Story to the Collective Intentions}

We report here and focus on the outcomes of one of the groups of the ST, composed by 9 students. Each one of them-before being located in a group-wrote an individual story, here synthetically represented and identified with the letters from "a" to "i" (Table 3):

We retraced the individual stories as functional choices - intended architecturally in the sense of destination and uses of the building - in order to highlight the individual intention of every participants about the renewal of Stock Exchange building. The functions span from a skate-park to a space for artistic exhibition and a study-room; at the same time, and despite all the possible conflicts and contradictions among individual perspectives, the participants have gathered and wrote a collective story. The collective story led to "Hi-DEAS. Homing i-nteractive District Extreme Art Sports", a name for the renewal intervention and the new Stock

Table 2 Second story-spine for writing a collective story
Second story-spine

1. Given the transformation you have individuated by your individual story, what are the necessary passages in order to effectively transform the place?

2. What could be the major issues and what are the strategies you can adopt to avoid those problems? 


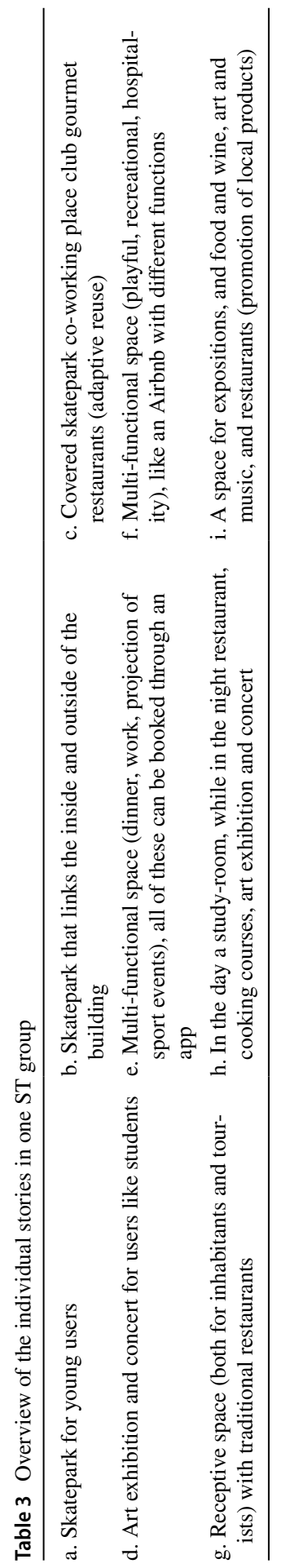


Exchange building. Hi-DEAS is a Multifunctional space devoted to manifold and different kinds of users (young and elder people), with a large skate-park space, art and painting laboratories, private kitchen that can be booked and a market with regional products.

What is the link between the collective and the individual? In this respect, we should see how the merging of intentions worked. We schematized it in the Table 4. Meshing different perspectives means to exclude some ideas in order that several can work together. In this respect students excluded in every group parts of the ideas proposed by participants. For instance, in this case ("Hi-DEAS") the group preferred to keep the skate-park instead of restaurants and a study room. They also discarded the hypothesis of a club within the wall of Stock Exchange building: skaters and club does do not get along because of the different kinds of user, and they took the decision of excluding the latter (Table 4).

The knowledge about what could be in the future the Stock Exchange building is in this case conveyed by stories. First individually and then-working on the individual perspectives-collectively. A concrete narrative-and somehow visual, as participants partly discussed and shared perspective through sketches and vignettes - acts in this case as a way of translating perspectives between those involved, with the effect of creating shared meanings and interpretations among participants. In this translation of perspective relies the aesthetics of the product: a well-formed narrative, with "its emplotment, the progression of action, the spacing and collocation of incidents (events)" (Coste 2017), is said to be (in the Western tradition, from Aristotle to present days) beauty. In one word, aesthetics/beauty is tied with (the Western) concept of narrative. Thus, the multiple individual intentions are negotiated to overcome conflicts in terms of different interpretations, that means traversing a semantics boundary and then sharing the undertaken and interpreted solutions in collective terms.

\subsubsection{Video}

The video (3 min 9 s) has been the more-than-final outcome of the workshop (Fig. 7). "More-than" because, as previously stated, professor did not ask for this kind of product; anyway, students decided to work on it autonomously. We analysed its aesthetic content by focusing on three points: time, place, and action (three main points for which Aristotle argued for their unity in Poetics).

First a brief summary of the plot. The video opens by focusing, and assuming, the individual perspective of a student. We are in front of the building, in a square where lot of young people skate in it. From a Facebook video he discovers that in the building there is a covered skate park, and a climbing wall. So, he goes there, he meets his friends and we assist to what we can call "love at first sight" between him and a girl that is going in the Stock Exchange building. They go inside, and we discover them while painting. Love spreads and the second time we see what there is in Stock Exchange building we discover the possibility to have a domestic kitchen, where you can cook and having a dinner-or lunch-with many friends. We see that he gives her a bracelet. The screen goes black and the camera frames two elderly 


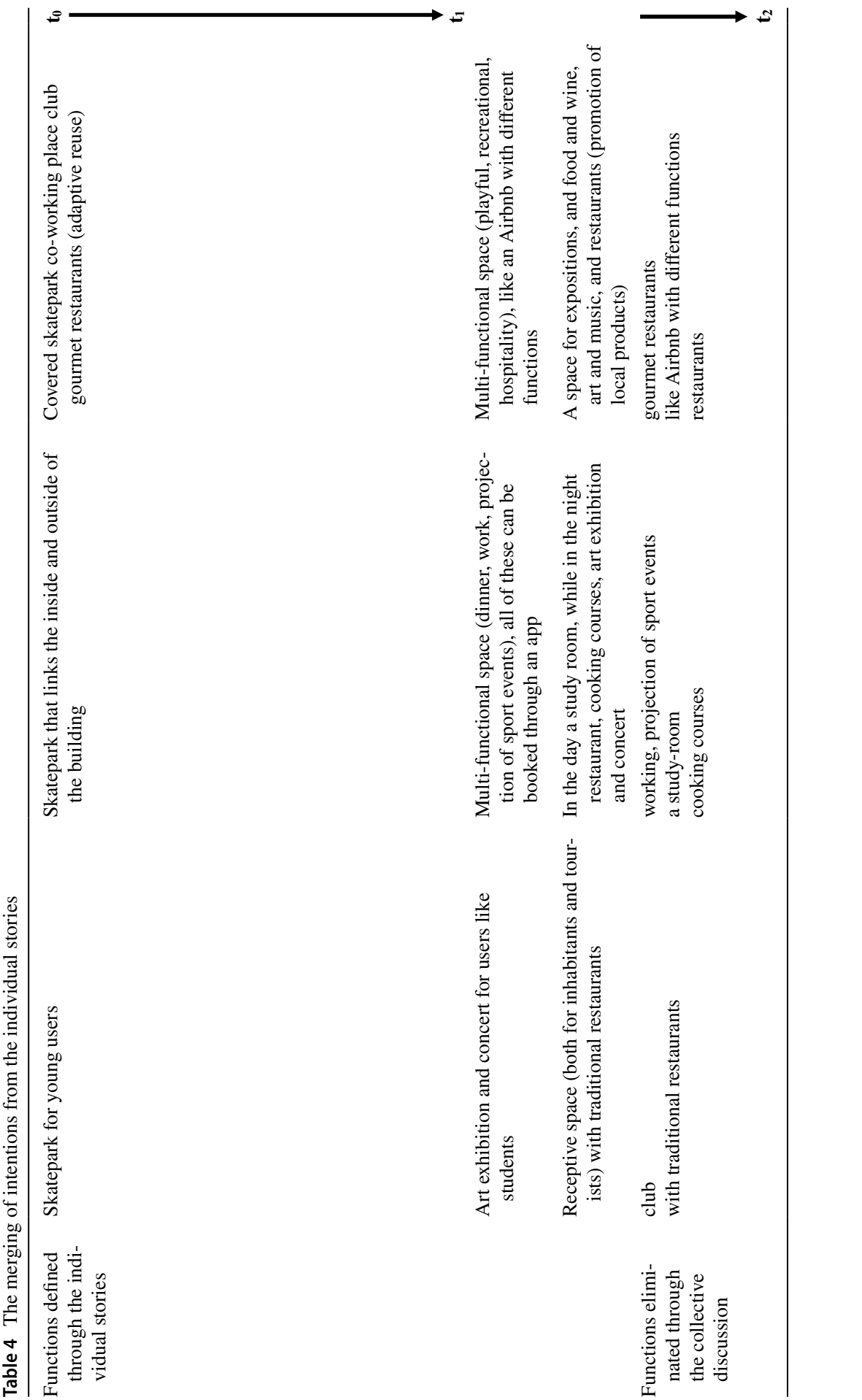




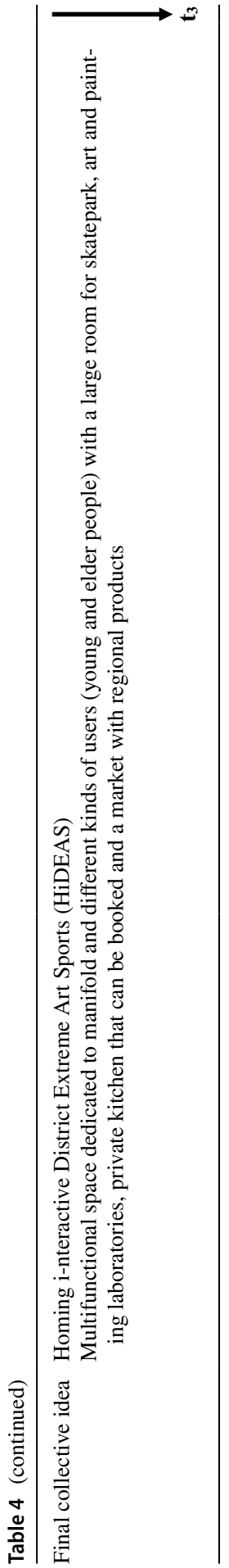



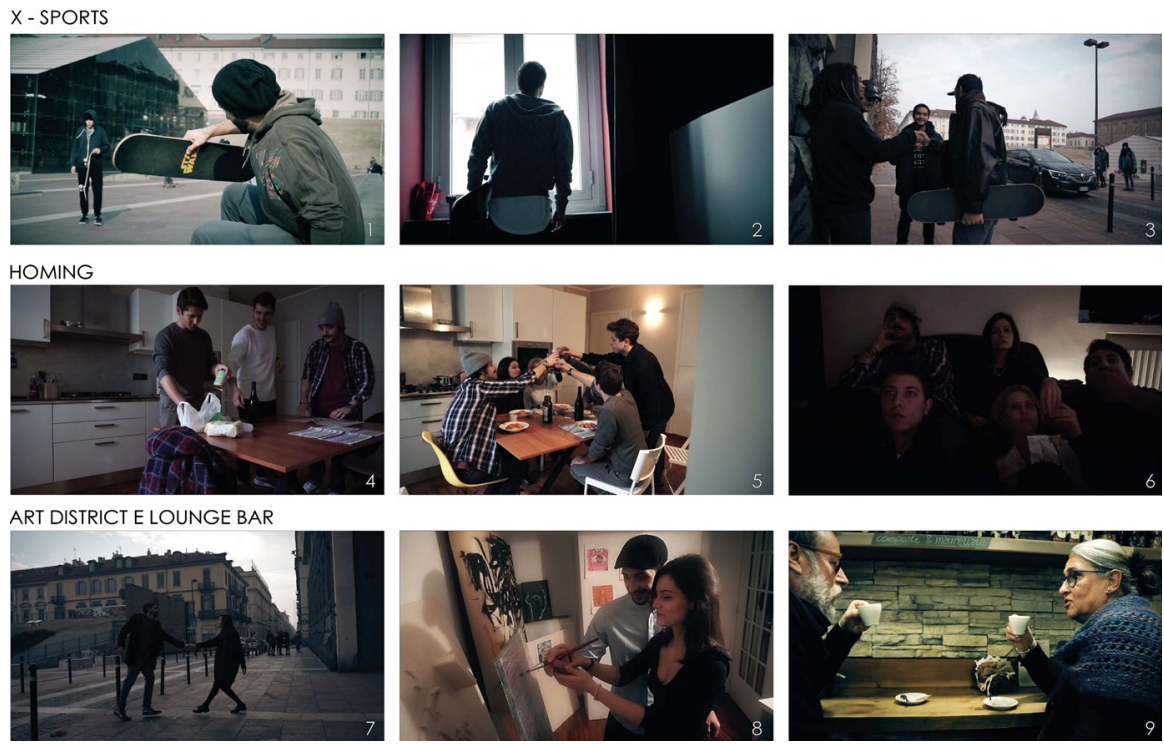

Fig. 7 Sketches from the video

people, a couple we think, they go inside the BV building, and they have a coffee in bar within its wall. The lady is wearing the same bracelet! A happy-ending story.

How does the knowledge convey? Following Mar and Oatley (2008), we can see how this video, a fiction, is a compressed unit of information and knowledge. The two scholars focus also in two other categories other than 'compression': abstraction and simplification. These three are categories through which interpret in what sense (fictional) narrative is a model of the social world. The focus here will be on the category of 'compression' because it highlights better than the others the aesthetic devices through which a knowledge is nested and shared within the group.

Compressing an information through a narrative device means the use of figures of speech, as metaphor, synecdoche, and metonymy. One of the most distinctive use of figures of speech within the video is the way we gradually became aware of the many functions within the building: every time they pass through the entrance (even in the Facebook video that the guy watches while it is raining): first a climbing wall, then a painting laboratory, a kitchen with a living room, one bar. Through the same action we know different sort of things and function. If we take in consideration the time within the video we have some very important information about Stock Exchange building: first, the transformation will be stable, even after forty years it still continues to work (the elderly versions of the main characters go inside it to have a coffee); second, the kind of users: both young guys and $60 \div 70$ years people. The last point of the analysis is the place of the video, one can intuitively think that all the video is in the building or in the immediate surroundings, but in the first scenes we see a Facebook video, and in this way the guy knows about the Stock Exchange building - that there is a climbing wall in it. This specific use of the 
"places" in the video show us also one possibility of communicating to potential future users about the existence of a new Stock Exchange building.

The video embodies here the aim of transforming perspectives in concrete visual reference, then the artefact acts managing - actually anticipating - the conflicts related to the consequences of particular choices in the project, through the inclusion of their implications. The visualization-as an aesthetic and concrete featureallows to share perspectives and to make concrete a perception, help participants to traverse a pragmatic boundary.

\section{Discussion}

As emerged in the analyses, models, artefacts, stories, and more in general aesthetic features perform here roles that help group members to specify, visualise, discuss and share their perspectives on a problem; moreover, since modelling transform the way this problem is intended in order to face it, new knowledge arises in this changing (Eden 1992; Franco 2013). Therefore, these aesthetic features act also as visible and mnemonic devices between participants, helping them in sharing, elaborating and negotiating their knowledge.

More in depth, in a focus on SCA and ST, two types of aesthetics emerge, in the first case with respect to the process, in the second case with respect to the product.

On the one hand, SCA is here investigated in its possible interface with architectural design, as a way of structuring cyclic processes of conflicts and negotiations. In SCA, drawings are used as an exchange object to generate effects and produce consequences in the process, within the group and among the participants. Then, in every step knowledge exchange through aesthetics is very linked to temporality and to the process: there are a number of cyclical moments of common knowledge and of reuniting the individual intentionality in the common "plural subject". The aesthetics lies in the way knowledge is exchanged and built during the process, gradually gathering all the instances. In this sense, we consider architectural design tools as a contribution to the creation of the so-called "invisible products" in SCA (Friend and Hickling 2005), enable to enlarge the participants' knowledge about the problem situation.

We suggest that joining SCA and architecture-through the creation and interaction on models and drawings within the SCA modes-consents a greater participation in the workshop by all the participants (White 2006; Todella et al. 2018; Tavella and Lami 2019). It does so by favouring the collective work and the interactivity of the process, thanks to a greater comprehensibility and simplicity in the knowledge around the problem (Eden 1992; Ackermann and Eden 2011; Franco 2013). It is also interesting to notice how the subdivision in sub-groups, that should have produced a decision's and work's detachment, incremented instead workflow and cohesion in each micro-group, actually, enabling a more informed and less conflictual discussion in the recomposed macro-groups.

Due to the "trait d'union", the division in subgroups, that could have had conflictual implications in decisions, allows instead a stronger collaboration and a 
more informed discussion in the macro-groups, thanks to the cohesion created in smaller subgroup, since the work has been carried out in a harmonious and productive way.

On the other, in ST the aesthetics of the product allows a global and overall view of the issue at the end, in a narrative way. In few words, the role of aesthetics within the individual story was to make able every participant to imagine, and visualize his/her own intentions about the future of the building; while in the collective story, and specifically in the video the participants made, the aesthetics acted not only as a tool for visualizing the future, but also for gluing together different intentions about the same future. In the collective story, the "plural subject" comes out, in a final step and product: in fact, the different individual narratives are collected and converge in order to compose something joint and collective. Then, in ST the aesthetic content is embedded in the narrative itself. The representation of the events as temporally ordered, causally correlated and unified under a common story expresses different emotions and represents parts of the reality (be it in the present, in the past or-as in this case-in the future). The aesthetic feature of ST then contributes to form a kind of knowledge which deals with the particular event or object narrated.

The compression through a narrative device shows us the way through which a knowledge can be shared and conveyed. The aesthetic perspective that we assumed makes able to look at the product not just a simple story, or chronicle of events, but as a product of imagination (not fantasy) that conveyed knowledge through a narrative of something that does not exist yet.

We then suggest that aesthetics — and aesthetic features as boundary objectsimplies and embodies functional knowledge in the decision-making process (SCA), on the one hand, or functional in the communication of the decision-making process, that is in the product (ST), on the other. It can be explained with the figure below (Fig. 8):

In this sense, aesthetics is more related, in SCA, to the creation of "invisible products" in the heart and souls of individuals that participate to the decision-making process and convey knowledge in the process functional for decision making.

method's artefacts
(stories or SCA models)
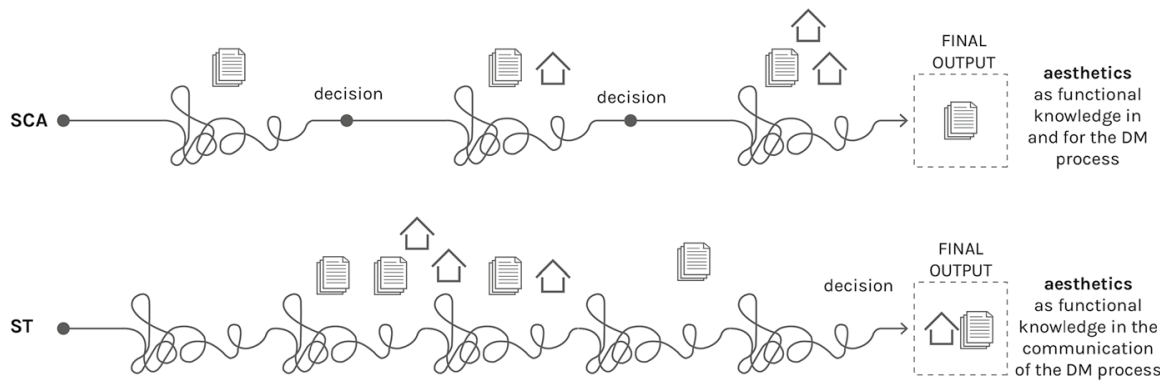

Fig. 8 Aesthetics' function in the SCA and ST decision-making processes 
In ST, aesthetics is in the process, of course (since participants use stories and images to discuss); however, it is more peculiar of the material effects and products of the process, that are meant to communicate and convey knowledge about the process, as also highlighted by the videos (see Fig. 8).

\section{Conclusions and Further Research}

Our study shows the importance of aesthetics in conveying knowledge about a problem in group decision and negotiation, and in contributing to create a "plural subject". In essence, we emphasised two kinds of aesthetics, one of the process and one of the product. Specifically, we highlight that in SCA aesthetics is more related to the creation of "invisible products" in individuals who participate to the decisionmaking process and convey knowledge in the process functional for decision making. In ST, despite the presence of aesthetics also in the process, the material effects and products of the process are more peculiar and they are meant to communicate the final decision.

The motivation for focusing our study on the aesthetics contribution in a specific decision problem field, the architecture, stems from the possibility of investigating SCA in its possible interface with architectural design, as a way of structuring cyclic processes of conflicts and negotiations; and from the aesthetic feature of ST that allows to look at the product as a product of imagination that conveyed knowledge through a narrative of something that does not exist yet (a building's renovation).

Employing a quasi-experimental research design, we were able to address our three concerns above. Specifically, we were able to show how in SCA, drawings are used as an exchange object to generate effects and produce consequences in the process, within the group and among the participants. Then, in every step knowledge exchange through aesthetics is very linked to temporality and to the process: there are a number of cyclical moments of common knowledge and of reuniting the individual intentionality in the common "plural subject". The aesthetics lies in the way knowledge is exchanged and built during the process, gradually gathering all the instances. As for the ST, we discussed how the aesthetics of the product allows a global and overall view of the issue at the end, in a narrative way. In the collective story, the "plural subject" comes out, in a final step and product: in fact, the different individual narratives are collected and converge in order to compose something joint and collective. Then, in ST the aesthetic content is embedded in the narrative itself. The representation of the events as temporally ordered, causally correlated and unified under a common story expresses different emotions and represents parts of the reality (be it in the present, in the past or-as in this case-in the future). The aesthetic feature of ST then contributes to form a kind of knowledge which deals with the particular event or object narrated.

As with all studies our study does have limitations, which we hope can provide directions for future research. First, the reflections illustrated are based on the data collected from few parallel workshops carried out with each method (SCA and ST). This aspect should be evaluated also considering the fact that the use of ST in PSMs is quite innovative. However, we carried out a fine-grained analysis aimed at 
exploring the phenomenon in depth and generating insights of theoretical importance. We recognise that the analysis of more workshops in different settings would have strengthened our conclusions. Second, due to time constraints, we did not carry out the entire approach of SCA, but only used them in part. Nevertheless, beings the aesthetics the focus of the paper, we can arguably affirm that the first two phases of SCA are the fundamental from this point of view. Third, our findings and conclusions are based on an experiment carried out with MSc students, whose behaviours and cognitions will be different from those of real decision makers. Finally, we acknowledge that facilitation vs. self-facilitation by the workshops participants may have influenced our results.

Despite these limitations, there is considerable potential for further research. In particular, it may be fruitful to investigate the role of aesthetics in GDN and in other contexts, not only in architectural field, in order to see if there are commonalities with our findings and stimulate a wider debate. Moreover, our study addresses call for more multi-methodology approaches, to investigate the different aesthetics contributions. In this sense, mention has to be made to the ongoing development of a new tool, SCA + (designed by second author of the paper, and tested in several settings also with third author), combining the first two SCA phases for shaping and designing the decisional problem and Analytic Hierarchic Process for the comparison step, which could represent an interesting field of study and verification.

Acknowledgements Open access funding provided by Politecnico di Torino within the CRUI-CARE Agreement.

Open Access This article is licensed under a Creative Commons Attribution 4.0 International License, which permits use, sharing, adaptation, distribution and reproduction in any medium or format, as long as you give appropriate credit to the original author(s) and the source, provide a link to the Creative Commons licence, and indicate if changes were made. The images or other third party material in this article are included in the article's Creative Commons licence, unless indicated otherwise in a credit line to the material. If material is not included in the article's Creative Commons licence and your intended use is not permitted by statutory regulation or exceeds the permitted use, you will need to obtain permission directly from the copyright holder. To view a copy of this licence, visit http://creativecommons.org/licen ses/by/4.0/.

\section{References}

Ackermann F, Eden C (2005) Using causal mapping with group support systems to elicit an understanding of failure in complex projects: some implications for organizational research. Group Decis Negot 14(5):355-376

Ackermann F, Eden E (2011) Negotiation in strategy making teams: group support systems and the process of cognitive change. Group Decis Negot 20:293-314

Andrews DH, Hull TD, Donhaue JA (2009) Storytelling as an instructional method: definitions and research questions. Interdiscip J Problem Based Learn 3(2):6-23

Armando A, Bonino M, Frassoldati F (2015) Watersheds. A narrative of urban recycle. Sandu Publishing Co, Guangzhou

Baumgarten AG (1750) Æsthetica. Ioannis Christiani Kleyb, Frankfurt a.d. Oder

Bratman M (1999) Faces of intention: selected essays on intention and agency. Cambridge University Press, Cambridge 
Bratman M (2014) Shared agency: a planning theory of acting together. Cambridge University Press, Cambridge

Bulkens M, Minca C, Muzaini H (2015) Storytelling as method in spatial planning. Eur Plan Stud 23(11):2310-2326

Carlile RP (2002) A pragmatic view of knowledge and boundaries: boundary objects in new product development. Organ Sci 13:442-455

Carlile RP (2004) Transferring, translating, and transforming: an integrative framework for managing knowledge across boundaries. Organ Sci 15:555-568

Checkland P (2001) Soft systems methodology. In: Rosenhead J, Mingers J (eds) Rational analysis for a problematic world revisited. Wiley, Chichester

Checkland P, Scholes J (1990) Soft systems methodology in action. Wiley, Chichester

Consoli G (2015) Estetica e scienze cognitive. il Mulino, Bologna

Coste D (2017) Narrative theory. Oxf Res Encycl Lit. https://doi.org/10.1093/acrefore/9780190201 098.013.116

Cushman M, Rosenhead J (2004) Planning in the face of politics: reshaping children's health services in inner London. In: Sainfort F, Brandeau M, Pierskalla W (eds) Handbook of OR/MS applications in health care. Kluwer, Boston, pp 559-595

Danto A (1981) The transfiguration of the commonplace. Harvard University Press, Cambridge

Eden C (1992) A framework for thinking about group decision support systems (GDSS). Group Decis Negot 1:199-218

Eden C, Pyrko I, Howick S (2017) Knowledge acquisition using group support systems. In: Schoop M, Kilgour DM (eds) Proceedings of the 17th international conference on group decision and negotiation. Stuttgart-Hohenheim, Germany, pp 381-386

Franco LA (2008) Facilitating collaboration with problem structuring methods: a case of an interorganisational construction partnership. Group Decis Negot 17(4):267-286

Franco LA (2013) Rethinking soft OR interventions: models as boundary objects. Eur J Oper Res 231(3):720-733

Franco LA, Montibeller G (2010) Facilitated modelling in operational research. Eur J Oper Res 205(3):489-500

Franco LA, Nielsen MF (2018) Examining group facilitation in situ: the use of formulations in facilitation practice. Group Decis Negot 27(5):735-756

Franco LA, Rouwette EAJA (2011) Decision development in facilitated modelling workshops. Eur J Oper Res 212(1):164-178

Franco LA, Rouwette EAJA, Korzilius H (2016) Different paths to consensus? The impact of need for closure on model-supported group conflict management. Eur J Oper Res 249(3):878-889

Friend S (2006) Narrating the truth (more or less). In: Kieran M, McIver Lopes D (eds) Knowing art: essays in aesthetics and epistemology. Springer, Dordrecht, pp 35-49

Friend J, Hickling A (2005) Planning under pressure: the strategic choice approach, 3rd edn. Pergamon, Oxford

Gilbert M (2014) Joint commitment: how we make the social world. Oxford University Press, Oxford

Goldie P (2012) The mess inside: narrative, emotion and the mind. Oxford University Press, Oxford

Herrera HJ, McCardle-Keurentjes MHF, Videira N (2016) Evaluating facilitated modelling processes and outcomes: an experiment comparing a single and a multimethod approach in group model building. Group Decis Negot 25(6):1277-1318

Keys P (2007a) Knowledge work, design science and problem structuring methodologies. Syst Res Behav Sci 24:523-535

Keys P (2007b) Reducing the process lacuna in operational research by taking a knowledge work perspective. Syst Res Behav Sci 24:285-296

Klein JH, Connell NAD, Meyer E (2007) Operational research practice as storytelling. J Oper Res Soc 58:1535-1542

Lami IM (2019) The context of urban renewals as a 'super-wicked' problem. Smart Innov Syst Technol 100:249-255

Lami IM, Tavella E (2019) On the usefulness of soft OR models in decision making: a comparison of problem structuring methods supported and self-organized workshops. Eur J Oper Res 275(3):1020-1036

Lami IM, Todella E (2019) Facing urban uncertainty with the strategic choice approach: the introduction of disruptive events. Rivista di Estetica 71(2/2019):222-240 
Lami IM, Abastante F, Bottero M, Masala E, Pensa S (2014) Integrating multicriteria evaluation and data visualization as a problem structuring approach to support territorial transformation projects. EURO J Decis Process 2:281-312. https://doi.org/10.1007/s40070-014-0033-x

Latour B (1988) Science in action: how to follow scientists and engineers through society. Harvard University Press, Cambridge

Latour B, Woolgar S (1979) Laboratory life: the construction of scientific facts. Sage Publications, Beverly Hills

Linstead S, Hopfl H (eds) (2000) The aesthetic of organization. Sage, London

Livingstone P (2009) Narrativity and knowledge. J Aesthet Art Crit 67(1):25-36

Mar RA, Oatley K (2008) The function of fiction is the abstraction and simulation of social experience. Perspect Psychol Sci 3(3):173-192

Midgley G, Cavana RY, Brocklesby J, Foote JL, Wood DRR, Ahuriri-Driscoll A (2013) Towards a new framework for evaluating systemic problem structuring methods. Eur J Oper Res 229(1):143-154

Mingers J, Brocklesby J (1997) Multimethodology: towards a framework for mixing methodologies. Omega Int J Manag Sci 25(5):489-509

Mingers J, Rosenhead J (2004) Problem structuring methods in action. EURO J Oper Res 152:530-554

Phillips LD, Phillips MC (1993) Facilitated work groups: theory and practice. J Oper Res Soc 44(6):533-549

Pidd M (2003) Tools for thinking: modelling in management science, 2nd edn. Wiley, Chichester

Ricoeur P (1984) Time and narrative, vol 1. University of Chicago Press, Chicago

Rittel HWJ, Webber MM (1973) Dilemmas in a general theory of planning. Policy Sci 4:155-169

Rouwette EAJA (2011) Facilitated modelling in strategy development: measuring the impact on communication, consensus and commitment. J Oper Res Soc 62:879-887

Searle J (1995) The construction of social reality. The Free Press, New York

Spradley JP (1980) Participant Observation. Holt, Rinehart and Winston, New York

Star SL, Griesemer RJ (1989) Institutional ecology, 'translations', and boundary objects: amateurs and professionals in Berkeley's museum of vertebrae zoology. Soc Stud Sci 19:387-420

Stigliani I, Ravasi D (2018) The shaping of form: exploring designers' use of aesthetic knowledge. Organ Stud 39(5-6):747-784

Tavella E, Franco LA (2015) Dynamics of group knowledge production in facilitated modelling workshops: an exploratory study. Group Decis Negot 24(3):451-475

Tavella E, Lami IM (2018) Negotiating perspectives and values through soft OR in the context of urban renewal. J Oper Res Soc 70(1):136-161

Tavella E, Lami IM (2019) Negotiating perspectives and values through soft OR in the context of urban renewal. J Oper Res Soc 70(1):136-161

Todella E, Lami IL, Armando A (2018) Experimental use of strategic choice approach (SCA) by individuals as an architectural design tool. Group Decis Negot 27(5):811-826

Tollefsen D, Gallagher S (2017) We-narratives and the stability and depth of shared agency. Philos Soc Sci 47(2):95-110

Tsoukas H (2005) Complex knowledge. Oxford University Press, Oxford

Tsoukas H (2009) A dialogical approach to the creation of new knowledge in organizations. Organ Sci 20(6):941-957

van Maanen J (1979) The fact of fiction in organizational ethnography. Adm Sci Q 24:539-550

Walton KL (2013) Fictionality and Imagination Reconsidered. In: Barbero C, Ferraris M, Voltolini A (eds) From fictionalism to realism. Cambridge Scholars Publishing, Newcastle upon Tyne, pp 9-26

White $\mathrm{H}$ (1980) The value of narrativity in the representation of reality. Crit Inq 7(1):5-27. https://doi. org/10.1086/448086

White L (2006) Aesthetics in OR/systems practice: towards a concept of critical imagination as a challenge to systems thinking. Syst Res 23:779-791

White L (2009) Understanding problem structuring methods interventions. Eur J Oper Res 199(3):823-833

White L, Burger K, Yearworth M (2016) Understanding behaviour in problem structuring methods interventions with activity theory. Eur J Oper Res 249:983-1004

Publisher's Note Springer Nature remains neutral with regard to jurisdictional claims in published maps and institutional affiliations. 